\title{
Risk Assessment of Exposure to Lead in Tap Water among Residents of Seri Kembangan, Selangor State, Malaysia
}

\author{
Lim C. S. ${ }^{1}$, Shaharuddin M. S. ${ }^{1} \&$ Sam W. Y. ${ }^{1}$ \\ ${ }^{1}$ Department of Environmental and Occupational Health, Faculty of Medicine and Health Sciences, Universiti \\ Putra Malaysia, Serdang, Selangor, Malaysia \\ Correspondence: Shaharuddin M. S., Department of Environmental and Occupational Health, Faculty of \\ Medicine and Health Sciences, Universiti Putra Malaysia, 43400 UPM Serdang, Selangor, Malaysia. E-mail: \\ shaha@medic.upm.edu.my
}

Received: September 20, 2012 Accepted: October 12, 2012 Online Published: November 22, 2012

doi:10.5539/gjhs.v5n2p1 URL: http://dx.doi.org/10.5539/gjhs.v5n2p1

\begin{abstract}
Introduction: A cross sectional study was conducted to estimate risk of exposure to lead via tap water ingestion pathway for the population of Seri Kembangan (SK). Methodology: By using purposive sampling method, 100 respondents who fulfilled the inclusive criteria were selected from different housing areas of SK based on geographical population distribution. Residents with filtration systems installed were excluded from the study. Questionnaires were administered to determine water consumption-related information and demographics. Two water samples (first-flushed and fully-flushed samples) were collected from kitchen tap of each household using HDPE bottles. A total of 200 water samples were collected and lead concentrations were determined using a Graphite Furnace Atomic Absorption Spectrophotometer (GFAAS). Results: Mean lead concentration in first-flushed samples was $3.041 \pm$ SD $6.967 \mu \mathrm{g} / \mathrm{L}$ and $1.064 \pm$ SD $1.103 \mu \mathrm{g} / \mathrm{L}$ for fully-flushed samples. Of the first-flushed samples, four (4) had exceeded the National Drinking Water Quality Standard (NDWQS) lead limit value of $10 \mu \mathrm{g} / \mathrm{L}$ while none of the fully-flushed samples had lead concentration exceeded the limit. There was a significant difference between first-flushed samples and fully-flushed samples and flushing had elicited a significant change in lead concentration in the water $(Z=-5.880, p<0.05)$. It was also found that lead concentration in both first-flushed and fully flushed samples was not significantly different across nine (9) areas of Seri Kembangan $(\mathrm{p}>0.05)$. Serdang Jaya was found to have the highest lead concentration in first-flushed water $($ mean $=10.44 \pm \mathrm{SD} 17.83 \mu \mathrm{g} / \mathrm{L}$ ) while Taman Universiti Indah had the highest lead concentration in fully-flushed water (mean=1.45 $\pm \mathrm{SD} 1.83 \mu \mathrm{g} / \mathrm{L}$ ). Exposure assessment found that the mean chronic daily intake (CDI) was $0.028 \pm \mathrm{SD} 0.034 \mu \mathrm{gday}^{-1} \mathrm{~kg}^{-1}$. None of the hazard quotient (HQ) value was found to be greater than 1 . Conclusion: The overall quality of water supply in SK was satisfactory because most of the parameters tested in this study were within the range of permissible limit and only a few samples had exceeded the standard values for lead and $\mathrm{pH}$. Non-carcinogenic risk attributed to ingestion of lead in SK tap water was found to be negligible.
\end{abstract}

Keywords: lead, first-flushed water, fully-flushed water, non-carcinogenic risk, Seri Kembangan

\section{Introduction}

Metals could exert effects that are beneficial or harmful to our human body (Caussy et al., 2003). Heavy metals are especially renowned for their toxicity effects towards human beings, aquatic life and the environment. Lead is one of the heavy metals which have no known physiologically relevant role in the body (White et al., 2007). Lead from environmental pollution is not carcinogenic, but even low dose lead exposure has been shown to have detrimental and long-lasting effects on the renal, hemopoietic and nervous system (Fertmann et al., 2004).

The main target for lead toxicity is the nervous system, both in adults and children (ATSDR, 1998). It can create irreversible intellectual impairment in infants and young children, even at blood lead levels below $10 \mathrm{mg} / \mathrm{dL}$ (Lanphear et al., 2000; Gump et al., 2008; Jusko et al., 2008). As exposure continues, the effect progresses with insomnia, confusion, impaired concentration, and memory problems (Robson, 2003).

Humans are continuously exposed to lead from natural as well as anthropogenic sources (Christensen, 1995). Since the introduction of unleaded petrol and total phased out of leaded petrol in 1998, the lead level in the atmosphere had declined significantly (DOE, 2011). In addition to exposure to lead in the air, ingestion of lead in drinking water has become one of the major sources of human exposures to lead (Matte et al., 2000). The 
presence of lead in drinking water is a public health problem due to their absorption and possible accumulation in organisms (Chiron et al., 2003).

Drinking water in the house can be contaminated by corrosion of the plumbing materials used to supply the houses (Gulson et al., 1994). Corrosion of household plumbing systems is an important source of lead found in tap waters (Calderon, 2000). Significant levels of trace metals may be detected after stagnation of the water in distribution systems, especially during night-time (Seifert et al., 2000).

In Malaysia, the water utilities are managed and operated by both state authority and concession companies following the privatization exercise in 1987 (Lee, 2004). The water supplied to consumers has actually been through treatment stages before being distributed. The treated water that is already safe for drinking will then be pumped to the balancing reservoirs before being distributed to service reservoirs (Konsortium Abass Sdn Bhd, 2010). Although the water is tested prior to supplying to the consumers, there might be some possibility of heavy metal contamination into the water supply during transfer and storage before going to households. Comparison of the water quality determined with available standards would be another interesting part of the study.

Lead in drinking water is a major public health concern. Risk from exposure to lead contaminated water will vary, depending on the individual, the circumstances, and the amount of water consumed. For example, infants who drink formula prepared with lead-contaminated water may be at a higher risk because of the large volume of water they consume relative to their body size (CDC, 2002). If there is good reason to believe that a person may have a significant source or combination of sources of lead exposure, bio-monitoring may be prudent (Payne, 2008). Exposure and associated health risk levels of exposure to lead in tap water of the SK population has not yet been investigated.

\section{Area Descriptions}

This cross sectional study was conducted to estimate the risk of exposure to lead via tap water ingestion pathway for the Seri Kembangan (SK) population. SK was selected as the study location because of its large population density with a total population of 66,481 people and there are many housing areas including Taman Sri Serdang, Taman Universiti Indah and Taman Sungai Besi Indah (Department of Statistics Malaysia, 2000). A study conducted by Abdullah (2008) found that the Semenyih Dam, which supplies raw water to be used in areas including Seri Kembangan, was actually contaminated with heavy metals such as lead, cadmium and copper. No similar studies have been conducted in SK as yet. The list of housing areas studied can be seen in Table 1 .

\section{Methodology}

The study population was the SK population, and the sampling unit was a resident living in SK who fulfilled the inclusion criteria, which were adult Malaysians ( $\geq 18$ years old) who use the tap water for drinking and cooking. The exclusive criteria were tap water which is not from municipal water supply and personal water filtration systems which are installed at the house.

The sample size of this study was 100 respondents. It was calculated based on a formula by Kirkwood (2003) and taken into consideration missing and damaged data. The sampling method in this study was purposive sampling method, where the respondents were selected based on inclusive and exclusive criteria stated. The number of samples to be collected from each area of SK was calculated according to the geographical population distribution as shown in Table 1. Data collection was carried out from 21st December 2010 until 9th February 2011. 
Table 1. Geographical population distribution and required water samples $(\mathrm{N}=100)$

\begin{tabular}{lll}
\hline Housing area & Population & Water samples \\
\hline Taman Serdang Raya & 13120 & 8 \\
Taman Serdang Jaya & 18190 & 12 \\
Taman Sri Serdang & 14360 & 9 \\
Taman Universiti Indah & 14330 & 9 \\
Taman Sungai Besi Indah & 8295 & 5 \\
Taman Belimbing Indah & 3430 & 2 \\
Taman Muhibah & 3640 & 2 \\
Kampung Baru Seri Kembangan & 10175 & 6 \\
Taman Bukit Serdang & 70960 & 45 \\
TOTAL & $\mathbf{1 5 6 5 0 0}$ & $\mathbf{1 0 0}$ \\
\hline
\end{tabular}

Source: Local Planning of Subang Jaya Municipal Council (2020).

\subsection{Study Instrumentation and Data Collection}

For each sampling unit, one person who fulfilled the inclusive criteria was invited to be the respondent. The questionnaire, which inquired about socio-demographics of occupants, health status, water supply and plumbing system in the house, was administered during the visit. The questionnaires were modified from the Baseline, Descriptive and Time-Activity Questionnaires used in NHEXAS-Arizona study (Lebowitz et al. 1995) and also from a study conducted by Kavcar (2006). The questionnaire was in Malay since Bahasa Malaysia is our national language and the language is understood by all the citizens.

In this study, $250 \mathrm{ml}$ high-density polyethylene (HDPE) bottles were used for sampling of tap water. HDPE bottles had previously been used in many studies to detect heavy metals in water (Shuhaimi-Othman et al., 2008, Kavcar et al., 2009; Cidu et al., 2010). Before sampling, the bottles were acid washed where they were soaked overnight in $10 \%$ acid nitric bath before being washed twice with distilled water. After drying in the oven, the bottles were tightly capped and sealed in plastic bags before transported to the site to avoid contamination from heavy metals the external environment.

Two water samples were collected from each house. The first water sample (first-flush sample) was the very first drops of cold water that came out from the kitchen tap after an overnight of stagnation. This sample determines whether lead accumulated in the water comes from the house's plumbing system. The second water sample (fully-flushed sample) was the water taken from the kitchen tap after flushing for 2 minutes. This sample determines if the main distribution system was the source of lead in the water.

Flow diagram of sampling technique is shown in Figure 1. Written consent was obtained from the respondent, who was given a written step-by-step instruction for collecting the water samples. The procedure followed method used by Vegesna \& McAnally (1995) and Rajaratnam et al. (2002). All HDPE bottles were collected within 6 hours of sampling. 


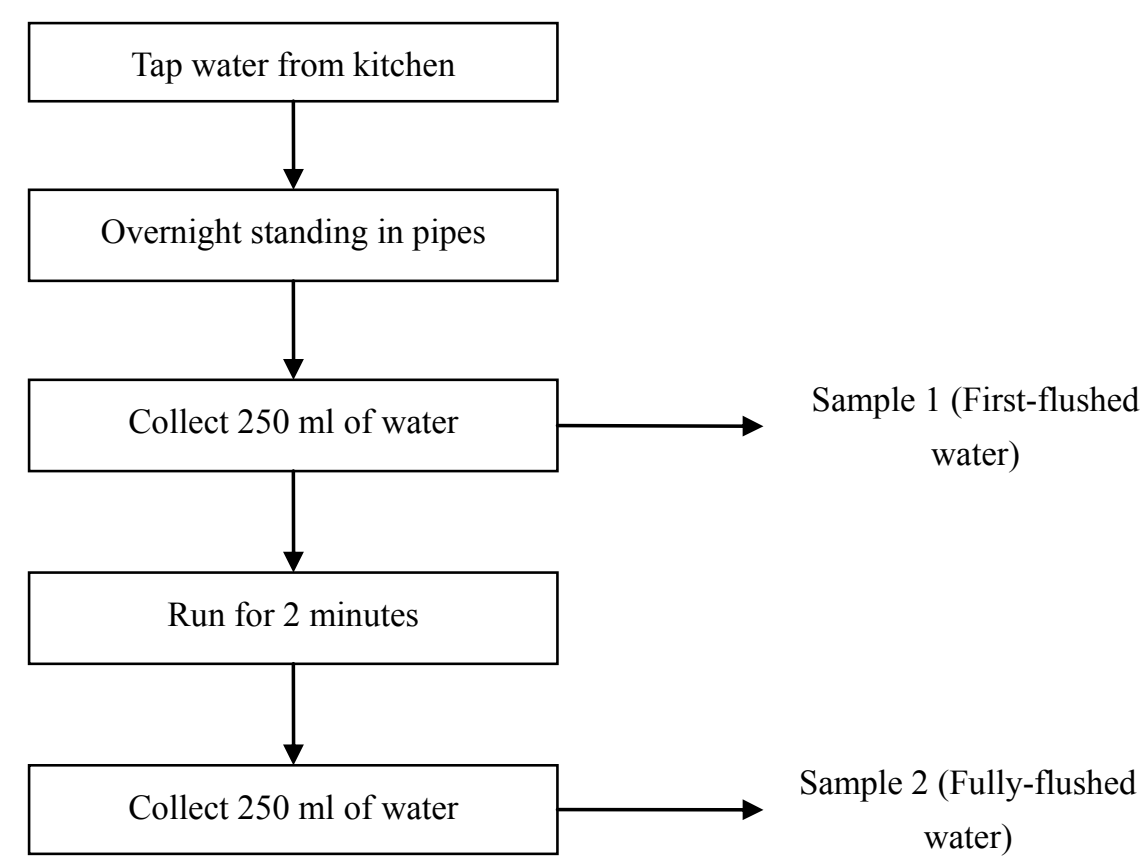

Figure 1. Flow diagram of sampling technique

The $250 \mathrm{ml}$ beakers were used to fill the fully flushed tap water for testing of conductivity, TDS, temperature and $\mathrm{pH}$. These parameters were measured directly in situ during collection of HDPE bottles from respondents (Angerville et al., 2007). Conductivity, total dissolved solid (TDS) and temperature were measured simultaneously using a HACH SensionTM5 conductivity meter while $\mathrm{pH}$ was measured using a LAMOTTE Tracer ORP Pocketester.

The measurement of lead content in water samples were performed using a Perkin Elmer AAnalyst 600 Graphite Furnace Atomic Absorption Spectrophotometer (GFAAS) equipped with the intuitive WinLab32 software, which featured the tools to analyze samples, report and archive data (Sarojam, 2011).

\subsection{Quality Control}

The analysis of water samples using GF-AAS model Perkin Elmer AAnalyst 600 followed the standard operating procedures (SOPs) as given by the manufacturer. Other instruments such as turbidity meter, $\mathrm{pH}$ meter and weighing scale were operated based on the SOPs of the respective equipment as well. Following SOPs could reduce errors due to analysis. All instruments were calibrated before use. For GF-AAS, a calibration curve of approximately 1 was obtained prior to analysis of water samples so that the absorption of the lead atom became more accurate. Pre-testing of questionnaires was conducted on $10 \%$ of sample size before data collection to ensure that every question asked in questionnaires could be easily understood and thus answered by respondents. Pre-testing was conducted on 10 households in Kajang area, approximately $10 \mathrm{kms}$ from the study area.

\subsection{Risk Assessment}

The following equation was used to calculate the daily exposure for ingestion route (US EPA, 1999; Chrostowski, 1994).

$$
C D I=\frac{(C \times D I)}{B W}
$$

Where, $\quad \mathrm{CDI}=$ Chronic daily intake $\left(\mu \mathrm{gkg}^{-1} \mathrm{day}^{-1}\right)$,

$\mathrm{C}=$ Lead concentration in water $\left(\mathrm{mgL}^{-1}\right)$,

$\mathrm{DI}=$ Average daily intake rate of water $\left(\mathrm{LDay}^{-1}\right)$,

$\mathrm{BW}=$ body weight $(\mathrm{kg})$.

Values of these three input variables, unique to each respondent, were used to estimate the respondent's 
individual chronic daily exposure level. The hazard quotient (HQ) was calculated to estimate non-carcinogenic risk using the following equation:

$$
H Q=C D I / R f D
$$

Where,

$$
\begin{aligned}
& \mathrm{HQ}=\text { Hazard quotient } \\
& \mathrm{R}_{\mathrm{f}} \mathrm{D}=\text { reference dose }\left(\mu \mathrm{gkg}^{-1} \text { day }^{-1}\right)
\end{aligned}
$$

A HQ value of $>1$ implied a significant risk level. $\mathrm{R}_{\mathrm{f}} \mathrm{D}$ value employed in this study was referred to Provisional Weekly Tolerable Intake (PWTI) of $25 \mu \mathrm{g}$ of lead per kg of body weight (equivalent to $3.5 \mu \mathrm{gkg}^{-1}$ of body weight per day) established by JECFA for infants and children but extended to all age groups in 1993 (WHO, 2003).

\section{Results}

\subsection{Sociodemographic Background}

The socio demographic data of respondents are summarized in Table 2. Respondents' age ranged from 18 to 74 years old, with a mean of $41.09 \pm$ SD 15.22 years old. The largest age group was $20-29$ years old $(29 \%)$. There were 34 Malays, 54 Chinese, 10 Indians and 2 other minority races who participated in the study. The mean body mass indexes (BMIs) of the respondents fell in the healthy and normal range of $25.34 \pm$ SD $6.56 \mathrm{kgm}^{-2}$. In the study, $26 \%$ of the respondents were degree holders, $23 \%$ of them had completed primary school education level while $4 \%$ of them did not receive any formal education. From the questionnaire, it was found that $48 \%$ of the respondents had monthly income of less than RM720, $12 \%$ of them have monthly income in the range of RM720 to RM1500, 25\% of them in the range of RM1501- RM2500 and $15 \%$ of them had a higher income of more than RM2500.

Table 2. Sociodemographic information $(\mathrm{n}=100)$

\begin{tabular}{lllll}
\hline Variable & Mean \pm S.D & Median & Min Value & Max Value \\
Age & $41.09 \pm 15.22$ & 40.50 & 18.00 & 74.00 \\
Weight $(\mathrm{kg})$ & $67.39 \pm 17.63$ & 64.00 & 42.00 & 157.00 \\
Height $(\mathrm{m})$ & $1.63 \pm 0.08$ & 1.63 & 1.45 & 1.78 \\
BMI $\left(\mathrm{kgm}^{-2}\right)$ & $25.34 \pm 6.56$ & 24.66 & 14.88 & 60.60 \\
\hline Variable & Category & Frequency & Percentage, \% & Cumulative Percentage \\
Gender & Male & 51 & 51 & 51 \\
& Female & 49 & 49 & 100 \\
Races & Malay & 34 & 34 & 34 \\
& Chinese & 54 & 54 & 88 \\
& Indian & 10 & 10 & 98 \\
Marital Status & Others & 2 & 2 & 100 \\
& Single & 35 & 35 & 35 \\
Highest Education Level & Married & 62 & 62 & 97 \\
& Divorced & 3 & 3 & 100 \\
& No schooling & 4 & 4 & 4 \\
& Primary school & 23 & 23 & 27 \\
& SRP/ PMR & 20 & 20 & 47 \\
& SPM & 13 & 13 & 60 \\
& STPM/ Diploma & 14 & 14 & 74 \\
& Degree & 26 & 26 & 100 \\
Monthly Income (RM) & $<720$ & 48 & 48 & 48 \\
& $720-1500$ & 12 & 12 & 60 \\
& $1501-2500$ & 25 & 25 & 85 \\
& $>2500$ & 15 & 15 & 100 \\
\hline
\end{tabular}




\subsection{Lead Concentrations in Water Samples}

The parameters tested in the water samples were lead concentration, temperature, $\mathrm{pH}$, TDS and conductivity. The results are summarized in Table 3. For lead concentrations in the first-flushed samples, the results ranged from $0.097 \mu \mathrm{g} / \mathrm{L}$ to $56.490 \mu \mathrm{g} / \mathrm{L}$. The mean lead concentration was $3.041 \pm \mathrm{SD}=6.967 \mu \mathrm{g} / \mathrm{L}$ while the median lead concentration was $1.313 \mu \mathrm{g} / \mathrm{L}$. As compared with National Drinking Water Quality Standard (NDWQS), the lead concentration in 4 first-flushed samples had exceeded the acceptable values of $10 \mu \mathrm{g} / \mathrm{L}$. For fully-flushed samples, the lead concentration ranged from $0 \mu \mathrm{g} / \mathrm{L}$ to $5.215 \mu \mathrm{g} / \mathrm{L}$. The mean lead concentration was $1.064 \pm \mathrm{SD} 1.103 \mu \mathrm{g} / \mathrm{L}$ with median of $0.702 \mu \mathrm{g} / \mathrm{L}$. None of the samples had surpassed the NDWQS value. Lead was not even found in 2 of the fully-flushed samples.

Table 3. Lead concentration and physical properties of water samples and the comparison with available standards

\begin{tabular}{lllllll}
\hline Parameters & $\begin{array}{l}\text { Lead concentration } \\
\text { in first-flushed } \\
\text { water }(\boldsymbol{\mu g} / \mathbf{L})\end{array}$ & $\begin{array}{l}\text { Lead concentration } \\
\text { in fully-flushed } \\
\text { water }(\boldsymbol{\mu g} / \mathbf{L})\end{array}$ & $\begin{array}{l}\text { Temperat } \\
\text { ure }\left({ }^{\circ} \mathbf{C}\right)\end{array}$ & $\mathbf{p H}$ & $\begin{array}{l}\text { Conduc } \\
\text { tivity } \\
(\boldsymbol{\mu S} / \mathbf{c m})\end{array}$ & $\begin{array}{l}\text { Total Dissolved } \\
\text { Solids, TDS } \\
(\mathbf{m g} / \mathbf{L})\end{array}$ \\
\hline Mean & 3.041 & 1.064 & 26.86 & 8.19 & 25.75 & 12.87 \\
Median & 1.313 & 0.702 & 27.35 & 8.08 & 26.30 & 13.15 \\
Std Deviation & 6.967 & 1.103 & 2.44 & 0.48 & 2.31 & 1.15 \\
$\mathbf{5}^{\text {th }}$ Percentile & 0.169 & 0.034 & 20.91 & 7.66 & 21.41 & 10.71 \\
$\mathbf{1 0}^{\text {th }}$ Percentile & 0.479 & 0.079 & 23.13 & 7.76 & 22.04 & 11.22 \\
$\mathbf{2 5}^{\text {th }}$ Percentile & 0.675 & 0.370 & 26.23 & 7.91 & 24.2 & 12.1 \\
$\mathbf{M e d i a n}^{\text {th }}$ Percentile & 1.313 & 0.702 & 27.35 & 8.08 & 26.3 & 13.15 \\
$\mathbf{7 5}^{\text {th }}$ Percentile & 5.546 & 1.445 & 28.3 & 8.31 & 27.3 & 13.68 \\
$\mathbf{9 5}^{\text {th }}$ Percentile & 8.133 & 2.473 & 29.09 & 8.73 & 28.3 & 14.1 \\
Min value & 0.097 & 4.057 & 30.47 & 9.58 & 28.7 & 14.3 \\
Max value & 56.490 & 0.000 & 19.2 & 7.16 & 16.88 & 8.4 \\
Drinking water & $10^{\mathrm{a}}$ & 5.215 & 31.6 & 9.79 & 30.60 & 15.3 \\
standards & & $10^{\mathrm{a}}$ & Not & $6.5-9^{\mathrm{a}}$ & $500^{\mathrm{b}}$ & $1000^{\mathrm{a}}$ \\
\hline
\end{tabular}

${ }^{\text {a }}$ National Drinking Water Quality Standard 2009

${ }^{\mathrm{b}}$ Water Supply (Water Quality) Regulations 1989

For other physical properties, none of the parameters had exceeded the NDWSQ and USEPA limit, except for pH value. There were 8 water samples which exceeded the NDWQS limit of $\mathrm{pH} 9$. However, the mean $\mathrm{pH}$ value which was 8.19 and median $\mathrm{pH}$ value of 8.08 were, in fact, in the range of acceptable value. Conductivity and TDS of water samples were far below the NDWQS limit. According to Table 4, no significant correlation was found between lead concentration and other physical properties of the water such as $\mathrm{pH}$, TDS, conductivity and temperature $(\mathrm{p}>0.05)$.

Table 4. Spearman Correlation of lead concentration with other physical properties

\begin{tabular}{|c|c|c|c|c|c|}
\hline $\begin{array}{l}\text { Lead } \\
\text { concentration }\end{array}$ & & $\begin{array}{l}\text { Conductivity } \\
(\mu \mathrm{S} / \mathrm{cm})\end{array}$ & TDS (mg/L) & pH & $\begin{array}{l}\text { Temperature } \\
\left({ }^{\circ} \mathrm{C}\right)\end{array}$ \\
\hline \multirow{3}{*}{$\begin{array}{l}\text { in first-flushed } \\
\text { water }(\mu \mathrm{g} / \mathrm{L})\end{array}$} & Correlation Coefficient & 0.129 & 0.131 & -0.116 & 0.167 \\
\hline & Sig. (2-tailed) & 0.200 & 0.195 & 0.252 & 0.097 \\
\hline & $\mathrm{n}$ & 100 & 100 & 100 & 100 \\
\hline \multirow{3}{*}{$\begin{array}{l}\text { fully-flushed } \\
\text { water }(\mu \mathrm{g} / \mathrm{L})\end{array}$} & Correlation Coefficient & 0.175 & 0.179 & 0.031 & 0.117 \\
\hline & Sig. (2-tailed) & 0.081 & 0.074 & 0.758 & 0.247 \\
\hline & $\mathrm{n}$ & 100 & 100 & 100 & 100 \\
\hline
\end{tabular}


The study showed that 78 first-flushed water samples had higher lead concentration than fully-flushed water. As shown in Table 5, there was a significant difference of lead concentration between first-flushed water and fully-flushed water, and first-flushed water has higher lead concentration as compared with fully-flushed water. Flushing had elicited a statistically significant change in lead concentration in the water $(Z=-5.880, p<0.05)$.

Table 5. Difference of lead concentration between first-flushed and fully-flushed water

\begin{tabular}{lllllll}
\hline Pair & Ranks & $\mathbf{n}$ & Mean Rank & Sum of Ranks & Z & p \\
\hline Lead concentration in & Negative Ranks & $78^{\mathrm{a}}$ & 54.29 & 4235.00 & & \\
fully-flushed water & Positive Ranks & $22^{\mathrm{b}}$ & 37.05 & 815.00 & $\mathbf{- 5 . 8 8 0}^{\mathbf{d}}$ & $\mathbf{0 . 0 1}$ \\
samples -first-flushed & Ties & $0^{\mathrm{c}}$ & & & \\
water samples & Total & 100 & & & \\
& & & & \\
\hline
\end{tabular}

${ }^{\text {a }}$ Lead concentration in fully-flushed water samples $<$ first-flushed water samples

${ }^{\mathrm{b}}$ Lead concentration in fully-flushed water samples $>$ first-flushed water samples

${ }^{c}$ Lead concentration in fully-flushed water samples $=$ first-flushed water samples

${ }^{\mathrm{d}}$ Based on positive rank

\subsection{CDI and HQ Values}

As summarized in Table 8, the mean daily drinking water intake rate value found in this study was 1.794L/Day while the mean body weight of the respondents was found to be $67.39 \mathrm{~kg}$ and median weight was $64 \mathrm{~kg}$. The CDI value ranged from 0 to $0.230 \mu \mathrm{gday}^{-1} \mathrm{~kg}^{-1}$, with mean CDI value at $0.028 \pm \mathrm{SD} 0.034 \mu \mathrm{gday}^{-1} \mathrm{~kg}^{-1}$ and median at $0.017 \mu$ gday $^{-1} \mathrm{~kg}^{-1}$. Mean HQ value was $0.008 \pm \mathrm{SD} 0.0097$ while the median was 0.0048 . None of the respondents had HQ level of more than 1. HQ values were less than 1 in the whole population indicated that the non-carcinogenic risk associated with exposure to lead in tap water via ingestion pathway was negligible.

Table 8. Daily intake rate of water, body weight and chronic daily intake, CDI

\begin{tabular}{lllll}
\hline Parameters & $\begin{array}{l}\text { Daily intake rate of } \\
\text { water } \mathbf{( L / d a y )}\end{array}$ & weight $\mathbf{( k g )}$ & $\mathbf{C D I}\left(\mathbf{\mu g d a y}^{\mathbf{- 1}} \mathbf{k g}^{\mathbf{- 1}}\right)$ & HQ \\
\hline Mean & 1.794 & 67.39 & .028 & 0.0080 \\
Median & 1.600 & 64.00 & .017 & 0.0048 \\
S.D. & 1.144 & 17.63 & .034 & 0.0097 \\
$75^{\text {th }}$ Percentile & 2.000 & 75.00 & .030 & \\
$90^{\text {th }}$ Percentile & 3.000 & 85.00 & .073 & 0.0208 \\
$95^{\text {th }}$ Percentile & 4.190 & 94.80 & .096 & 0.0275 \\
$99^{\text {th }}$ Percentile & 7.586 & 156.83 & .226 & 0.0645 \\
Minimum & .400 & 42.00 & .000 & 0.0000 \\
Maximum & 7.600 & 157.00 & .230 & 0.0647 \\
\hline
\end{tabular}

\section{Discussion}

5.1 Lead Concentrations and Physical Properties of Water Samples and the Comparison with Available Water Standards

No similar study assessing the risk of exposure to lead in tap water was found in Malaysia. However, a study from Saraswathy (2009) at the Sunway residential area found that lead concentration in 4 stagnant water samples collected from consumer taps had actually exceeded the NSDWQ value of $10 \mu \mathrm{g} / \mathrm{L}$.

Rajaratnam et al. (2002) found that lead level in first-flushed water in the Sydney metropolitan area was very high, with a mean lead content of $29 \pm \mathrm{SD}=42 \mu \mathrm{g} / \mathrm{L}$. The study found that $60 \%$ of the first-flushed water samples collected was higher than the Australian Drinking Water Guidelines (ADWG) limit value of 10 $\mu \mathrm{g} / \mathrm{L}$. As compared with this study, the mean lead concentration from the Sydney study was around 10 times higher than in SK in first-flushed water samples. The huge difference of lead concentration may be due to age of houses. The study by Rajaratnam et al. focused only on new houses while this study did not take into consideration the 
age of house as the inclusive criteria for sampling. Sharrett et al. (1992) found that new housing areas of less than 5 years old or residence in which recent plumbing renovation or repairs had been completed, has the potential of producing higher lead exposure than older housing areas because the combination of copper piping with lead solder produces galvanic corrosion that can leach lead even in relatively non-corrosive water. Soldered connections in recently built homes fitted with copper piping can release enough lead (210-390 $\mu \mathrm{g} / \mathrm{l})$ to cause intoxication in children (Cosgrove et al., 1989).

A study done by Fertmann et al. (2004) in Hamburg, Germany found that less than $25 \%$ of the fresh water samples taken after 3 minutes of flushing had exceeded $10 \mu \mathrm{g} / \mathrm{L}$ among 248 water samples collected. It showed that lead concentration in flushed sample was low. A similar finding by Kavcar (2009) showed that lead was only detected in $15 \%$ of the drinking water samples collected. The concentration of lead was too low that it was undetectable in the rest of the samples.

In this study, the mean $\mathrm{pH}$ value which was 8.19 and median $\mathrm{pH}$ value of 8.08 were in the range of acceptable value. The result was similar with the study by Zietz et al. (2003) in Lower Saxony, Germany who found that tap water was slightly basic and the mean $\mathrm{pH}$ value was 7.83. According to Konsortium Abass Sdn Bhd, which is the operator for the Sungai Semenyih Water Supply Scheme, lime is added to the treated water to adjust the $\mathrm{pH}$ to the specific level. It was an alkaline compound that was added to neutralize the effect of alum, which was an acidic salt. It was important to increase the $\mathrm{pH}$ value of drinking water because a $\mathrm{pH}$ below 7 indicated an acidic water condition which is corrosive to metal pipes. This not only means that the pipes and faucets can be damaged by low $\mathrm{pH}$ water, but also that the water can contain high levels of copper, lead, or zinc that have corroded out of the plumbing systems (ATSDR, 2007).

Total dissolve solids (TDS) is the term used to describe the inorganic salts and small amounts of organic matter present in solution in water while conductivity is a measure of the conductance of water to an electric current. The conductivity values indicated the high mineralization of the samples. In this study, mean TDS and conductivity values of the water were far below drinking water standards. Unlike SK, TDS and conductivity value of tap water samples in Haiti were found to be very high and exceeding the limit value (Angerville et al., 2004). Reliable data on possible health effects associated with the ingestion of TDS in drinking water were not available (WHO, 1996).

\subsection{Correlation of Lead Concentration with other Physical Properties}

For $\mathrm{pH}$, the result was consistent with the study done by Kim and Herrera (2011), that significant correlations between lead concentrations and $\mathrm{pH}$ were not observed. Le et al. (2003) concluded that there was no correlation between lead in tap water and $\mathrm{pH}$ levels as well. However, in a study of drinking water with a low alkalinity and a fairly low $\mathrm{pH}$, high levels of lead were found in the drinking water of households that had lead plumbing (McFarren et al., 1977). In this study, $\mathrm{pH}$ was not significantly correlated with lead concentration most probably because the $\mathrm{pH}$ level of the water samples were just slightly alkali, with a mean of 8.19 , and generally at low $\mathrm{pH}$ levels only $(<6.8)$, most metals would corrode more rapidly than at higher $\mathrm{pH}(>9.0)$ (Schock \& Gardels, 1983).

In this study, temperature was not correlated with lead in tap water. The study was inconsistent with other studies which found that seasonal variations in temperature between the summer and winter months were correlated with lead concentrations, with the warmer temperatures of the summer months increasing lead concentrations (Karalekas et al., 1983; Colling et al., 1987; Douglas et al., 2004). This inconsistency might be due to the temperature of water samples did not vary much as Malaysia was a tropical country with hot weather all year round, as compared with studies done in other countries where extreme temperature changes are common especially during the winter and summer months.

TDS and conductivity were found to be not correlated with lead concentration in water samples. Although there was no correlation between TDS and lead concentration, there were studies suggested that certain components of TDS, such as chlorides, sulphates, magnesium, calcium, and carbonates, affect corrosion or encrustation in water-distribution systems. High TDS levels $(>500 \mathrm{mg} / \mathrm{L})$ resulted in excessive scaling in water pipes, and one must consider that lead concentration in tap water was contributed mainly by the corrosion of pipes (WHO, 1996).

\subsection{Comparison of Lead Concentration in First-Flushed and Fully Flushed Samples}

The result was consistent with a study done in Sydney, where lead concentrations were significantly different in the three types of samples. Multiple-comparison tests showed that lead levels in first-flushed samples were significantly higher than those in either post first-flushed or fully flushed samples (Rajaratnam et al., 2001).

The finding that first-flushed samples had higher lead concentration than fully-flushed samples was generally in 
agreement with other literature (Gulson et al., 1994; Schock et al., 1988; Levin, 1986; Sharrett et al., 1982). The difference might be due to standing time of water in the pipes. Several studies had found that first-flushed water had higher lead concentration than fully-flushed water because of the standing time. Schock et al. (1996) concluded that lead levels rapidly increase upon stagnation, but ultimately approach a fairly constant equilibrium value after overnight stagnation. Lytle and Schock (2000) showed that lead levels increased rapidly with the stagnation time of the water, with the most critical period being during the first 20-24 hours.

Since the level of trace metals increased upon stagnation of water, flushing the water present in the plumbing system would significantly reduce the levels of lead and copper. A study by Gardels et al. (1989) showed that $60-75 \%$ of the lead leached from common kitchen faucets appears in the first $125 \mathrm{~mL}$ of water collected from the faucet. In a study on contamination of tap water by lead solders, Wong and Berrang (1976) concluded that the first $2 \mathrm{~L}$ of water from cold water taps should not be used for human consumption if the water has been stagnant for a day. In Canadian studies, in which the cold water tap of homes was flushed for 5 minutes, no levels of trace metals exceeded their respective Canadian drinking water guidelines (Méranger et al., 1981; Singh and Mavinic, 1991).

\subsection{Exposure and Risk Assessment}

The exposure assessment in this study was done based on deterministic approach. In this approach, exposure estimated individually for each subject using his own body weight and daily intake rate of water instead of using USEPA daily intake rate of water default value of $2 \mathrm{~L} /$ day and an adult weight of $70 \mathrm{~kg}$. It was to avoid overestimation or underestimation of population risk (Kavcar et al., 2006).

The mean value for SK population was found to be close to the USEPA default value of $2 \mathrm{~L} /$ day. Many studies had found that the daily intake rate of water were different across different regions and countries due to different climate. Gillies and Paulin (1983) suggested an average daily water intake rate of 1.256L/Day and a 90th percentile rate of $1.9 \mathrm{~L} /$ Day on the basis of a survey conducted in New Zealand. A study done in Korea found that the daily intake rate of water was $2.56 \mathrm{~L} /$ day (Ji et al., 2009).

Daily water intake rate of the SK population was found to be less than USEPA default value of 2L. The reason might be due to the weather. As stated earlier, the data collection was conducted from late December until early February. According to the Malaysian Meteorological Department, December and January are the months with the lowest average monthly temperature. When the weather is cooler, the daily water consumption will become less. It was supported by study of Kavcar et al. (2006) who found that daily intake rate of water varies according to climatic condition.

The values for respondents' weight were found less than the value suggested by the USEPA (70 $\mathrm{kg})$ and used in many studies (Williams et al., 2002; Lee et al., 2004). If the body weight was assumed to be $70 \mathrm{~kg}$ for the SK population, exposure and risk would have been underestimated for female participants and overestimated for male participants. Chronic daily intake (CDI) was calculated for each respondent based on his daily intake rate of water, body weight and the lead concentration found in fully-flushed water.

In order to estimate risk, hazard quotient, $\mathrm{HQ}$ was calculated by dividing CDI by the reference dose, $\mathrm{R}_{\mathrm{f}} \mathrm{D}$ of $3.5 \mu \mathrm{g} / \mathrm{kg}$ of body weight per day as suggested by JECFA. The HQ values were found ranged from 0 to 0.0647 . HQ values were less than 1 in the whole population indicated that the non-carcinogenic risk associated with exposure to lead in tap

\subsection{Study Limitations}

There were three main limitations in this study. The first limitation was that only the ingestion route was taken into consideration in order to assess exposure associated with lead in drinking water. The second limitation was recall bias as the daily intake rate of water was determined not based on respondent's water intake rate in 7 consecutive days, but by asking the respondents to recall back the daily water intake rate using standard cup of $200 \mathrm{ml}$. Besides, there was a big variation of number of water samples collected from each housing area that the lead concentration in the water samples from these areas could not be compared statistically. For example, 48 water samples were collected from Taman Bukit Serdang but only 11 water samples were collected from Taman Serdang Jaya. It was because the number of water samples collected was determined by the geographical population distribution where the number of water samples collected was a representative of the population distribution in that area. 


\section{Conclusion}

The overall quality of water supply in SK was found to be satisfactory because most of the parameters tested in this study were within the range of permissible limit and only a few samples had exceeded the standard values for lead concentration and $\mathrm{pH}$ values. The study also found that first-flushed samples had higher lead concentration than fully-flushed samples and flushing would significantly reduce the levels of lead. In conclusion, none of the respondents was found to have HQ level more than 1, indicated that the non-carcinogenic risk of exposure to lead in tap water among residents of SK was negligible. Although the risk is negligible, we have to realize that the maximum permissible levels of elements established by the WHO and national legislations are generally based on toxicological studies on animals. Little is known in relation to the long-term human exposure to harmful elements in water. More research and surveillance studies should be conducted to determine exposure on the Malaysian population with regards to trace metals, especially lead in drinking water and to know the long-term effect of these elements to human health.

\section{Acknowledgements}

The authors would like to thank Madam Norijah bte Kassim, Madam Ardiana Naim, Mr. Mohd Noor bin Ali Piah and Madam Norshazana binti Nordin for their sincere help.

\section{References}

Abdullah, M. (2008). Water quality studies of semenyih dam. Other Thesis, Universiti Teknologi MARA (UiTM).

Calderon, R. L. (2000). The epidemiology of chemical contaminants of drinking water. Food and Chemical Toxicology, 38(Supplement 1), S13-S20. http://dx.doi.org/10.1016/S0278-6915(99)00133-7

Caussy, D., Gochfeld, M., Gurzau, E., Neagu, C., \& Ruedel, H. (2003). Lessons from case studies of metals: Investigating exposure, bioavailability, and risk. Ecotoxicology and Environmental Safety, 56(1), 45-51. http://dx.doi.org/10.1016/S0147-6513(03)00049-6

Centers for Disease Control and Prevention (U.S.). (2002). Managing elevated blood lead levels among young children: Recommendations from the advisory committee on childhood lead poisoning prevention Atlanta, GA : U.S. Dept. of Health and Human Services, Centers for Disease Control and Prevention.

Chiron, N., Guilet, R., \& Deydier, E. (2003). Adsorption of cu(II) and pb(II) onto a grafted silica: Isotherms and kinetic models. Water Research, 37(13), 3079-3086. http://dx.doi.org/10.1016/S0043-1354(03)00156-8

Chrostowski, P. (1994). Risk assessment and accepted regulatory cleanup levels. Remediation Journal, 4(4), 383-398. http://dx.doi.org/10.1002/rem.3440040402

Cidu, R., Frau, F., \& Tore, P. Drinking water quality: Comparing inorganic components in bottled water and italian tap water. Journal of Food Composition and Analysis, In Press, Corrected Proof.

Colling, J. H., Whincup, P. A. E., \& Hayes, C. R. (1987). The measurement of plumbosolvency propensity to guide the control of lead in tapwaters. Water and Environment Journal, 1(3), 263-269. http://dx.doi.org/10.1111/j.1747-6593.1987.tb01224.x

Cosgrove. (1989). Childhood lead poisoning: case study traces source to drinking water. Journal of environmental health, 52, 346.

Department of Environment. (2011). Air Quality Treand. Retrieved on March 5, 2011, from http://www.doe.gov.my/old/?q=en/content/air-quality-trend

Department of Statistics Malaysia. (2000). Population distribution by local authority areas and mukims. Population and Housing Cencus of Malaysia 2000.

Douglas, I., Guthmann, J., Muylwyk, Q., \& Snoeyink, V. (2004). Corrosion control in the city of ottawa--comparison of alternatives and case study for lead reduction in drinking water. 11th Canadian National Drinking Water Conference and Second Policy Forum. Calgary, Alberta, Canada. April, 3-6.

Fertmann, R., Hentschel, S., Dengler, D., Janßen, U., \& Lommel, A. (2004). Lead exposure by drinking water: An epidemiologial study in hamburg, germany. International Journal of Hygiene and Environmental Health, 207(3), 235-244. http://dx.doi.org/10.1078/1438-4639-00285

Gardels, M. C., \& Sorg, T. J. (1989). A laboratory study of the leaching of lead from water faucets. Journal of the American Water Resources Association, 81(7), 101-113.

Gillies, M. E., \& Paulin, H. V. (1983). Variability of mineral intakes from drinking water: A possible explanation for the controversy over the relationship of water quality to cardiovascular disease. International Journal of 
Epidemiology, 12(1), 45-50. http://dx.doi.org/10.1093/ije/12.1.45

Gulson, B. L., Law, A. J., Korsch, M. J., \& Mizon, K. J. (1994). Effect of plumbing systems on lead content of drinking water and contribution to lead body burden. The Science of the Total Environment, 144(1-3), 279-284. http://dx.doi.org/10.1016/0048-9697(94)90447-2

Gump, B. B., Stewart, P., Reihman, J., Lonky, E., Darvill, T., Parsons, P. J., et al. (2008). Low-level prenatal and postnatal blood lead exposure and adrenocortical responses to acute stress in children. Environmental Health Perspectives, 116(2), 249-255. http://dx.doi.org/10.1289/ehp.10391

Ji, K., Kim, Y., \& Choi, K. (2010). Water intake rate among the general korean population. Science of the Total Environment, 408(4), 734-739. http://dx.doi.org/10.1016/j.scitotenv.2009.10.076

Jusko, T. A., Henderson, C. R., Lanphear, B. P., Cory-Slechta, D. A., Parsons, P. J., \& Canfield, R. L. (2008). Blood lead concentrations $<10 \mathrm{microg} / \mathrm{dL}$ and child intelligence at 6 years of age. Environmental Health Perspectives, 116(2), 243-248. http://dx.doi.org/10.1289/ehp.10424

Karalekas, P., Ryan, C. R., \& Taylor, F. B. (1983). Control of lead, copper, and iron pipe corrosion in boston. $J$ Am Water Works Assoc, 75(2), 92-95.

Kavcar, P., Odabasi, M., Kitis, M., Inal, F., \& Sofuoglu, S. C. (2006). Occurrence, oral exposure and risk assessment of volatile organic compounds in drinking water for izmir. Water Research, 40(17), 3219-3230. http://dx.doi.org/10.1016/j.watres.2006.07.002

Kavcar, P., Sofuoglu, A., \& Sofuoglu, S. C. (2009). A health risk assessment for exposure to trace metals via drinking water ingestion pathway. International Journal of Hygiene and Environmental Health, 212(2), 216-227. http://dx.doi.org/10.1016/j.ijheh.2008.05.002

Kim, E. J., Herrera, J. E., Huggins, D., Braam, J., \& Koshowski, S. Effect of pH on the concentrations of lead and trace contaminants in drinking water: A combined batch, pipe loop and sentinel home study. Water Research, In Press, Accepted Manuscript.

Kirkwood, B. R., Sterne, J. A. C., \& Kirkwood, B. R. (2003). Essential medical statistics.

Konsortium Abass Sdn Bhd. (2010). Water treatment process. Retrieved on March 5, 2011, from $\mathrm{http}: / /$ www.abass.com.my/ABASS/index.php?option=com_content\&view=article\&id=89\&Itemid=79

Lanphear, B. P., Dietrich, K., Auinger, P., \& Cox, C. (2000). Cognitive deficits associated with blood lead concentrations $<10 \mathrm{microg} / \mathrm{dL}$ in US children and adolescents. Public Health Reports (Washington, D.C.: 1974), 115(6), 521-529. http://dx.doi.org/10.1093/phr/115.6.521

Le, V., Gansky, S., \& Newbrun, E. (2003). Fluoride and lead concentrations related to pH in drinking water. 32nd Annual Meeting and Exhibition of the AADR.

Lebowitz, M. D., O'Rourke, M. K., Gordon, S., Moschandreas, D. J., Buckley, T., \& Nishioka, M. (1995). Population-based exposure measurements in arizona: A phase I field study in support of the national human exposure assessment survey. Journal of Exposure Analysis and Environmental Epidemiology, 5(3), 297-325.

Lee, S. C., Guo, H., Lam, S. M. J., \& Lau, S. L. A. (2004). Multipathway risk assessment on disinfection by-products of drinking water in hong kong. Environmental Research, 94(1), 47-56. http://dx.doi.org/10.1016/S0013-9351(03)00067-7

Levin, R. (1986). Reducing lead in drinking water; a benefit analysis.

Lytle, D., \& Schock, M. (2000). Impact of stagnation time on metal dissolution from plumbing materials in drinking water. Aqua, 49, 243-257.

Matte, T., \& Jacobs, D. (2000). Housing and health-Current issues and implications for research and programs Springer New York.

McFarren, E., Buelow, R., Thurnau, R., Gardels, M., Sorrell, R., Snyder, P., et al. (1977). Water quality deterioration in the distribution system. Water Quality Technology Conference, Kansas City, MO.

Meranger, J. C., Subramanian, K. S., \& Chalifoux, C. (1981). Survey for cadmium, cobalt, chromium, copper, nickel, lead, zinc, calcium, and magnesium in canadian drinking water supplies. Journal - Association of Official Analytical Chemists, 64(1), 44-53.

Payne, M. (2008). Lead in drinking water. CMAJ: Canadian Medical Association Journal = Journal De l'Association Medicale Canadienne, 179(3), 253-254. http://dx.doi.org/10.1503/cmaj.071483 
Rajaratnam, G., Winder, C., \& An, M. (2002). Metals in drinking water from new housing estates in the sydney area. Environmental Research, 89(2), 165-170.

Robson, M. (2003). Methodologies for assessing exposures to metals: Human host factors. Ecotoxicology and Environmental Safety, 56(1), 104-109. http://dx.doi.org/10.1016/S0147-6513(03)00054-X

Angerville, R., Emmanuel, E., Joseph, O., \& Perrodin, Y. (2007). Human health risk assessment of lead in drinking water: A case study from port-au-prince, haiti. International Journal of Environment and Pollution, 31(3/4), 280 - 291.

Saraswathy, N. (2009). Determination of metals in tap water using atomic absorption spectrometry: a case study in bandar Sunway residential area. Sunway Academic Journal, 6, 33.

Sarojam, P. (2011). Analysis of Arsenic, Cadmium and Lead in Chinese Spice Mixtures using Graphite Furnace Atomic Absorption Spectrophotometry. SciTopics. Retrieved April 2, 2011, from http://www.scitopics.com/Analysis_of_Arsenic_Cadmium_and_Lead_in_Chinese_Spice_Mixtures_using Graphite_Furnace_Atomic_Absorption_Spectrophotometry.html

Schock, M. R., \& Gardels, M. C. (1983). Plumbosolvency reduction by high pH and low carbonate-solubility relationships. J. Am. Water Works Assoc., 75(2), 87-91.

Schock, M. R., \& Neff, C. H. (1988). Trace metal contamination from brass fittings. Journal American Water Works Association, 80(11), 47-56.

Schock, M. R., Wagner, I., \& Oliphant, R. (1996). The corrosion and solubility of lead in drinking water. Internal Corrosion of Water Distribution Systems, 131-230.

Seifert, B., Becker, K., Helm, D., Krause, C., Schulz, C., \& Seiwert, M. (2000). The german environmental survey 1990/1992 (GerES II): Reference concentrations of selected environmental pollutants in blood, urine, hair, house dust, drinking water and indoor air. Journal of Exposure Analysis and Environmental Epidemiology, 10(6 Pt 1), 552-565. http://dx.doi.org/10.1038/sj.jea.7500111

Sharrett, A. R., Carter, A. P., Orheimt, R. M., \& Feinleib, M. (1982). Daily intake of lead, cadmium, copper, and zinc from drinking water: The seattle study of trace metal exposure. Environmental Research, 28(2), 456-475. http://dx.doi.org/10.1016/0013-9351(82)90142-6

Shuhaimi-Othman, M., Mushrifah, I., Lim, E. C., \& Ahmad, A. (2008). Trend in metals variation in tasik chini, pahang, peninsular malaysia Springer Netherlands.

Singh, I., \& Mavinic, D. S. (1991). Significance of building and plumbing specifics on trace metal concentrations in drinking water. Canadian Journal of Civil Engineering, 18(6), 893-903. http://dx.doi.org/10.1139/191-111

United States. Environmental Protection Agency. Risk Assessment Forum. (1999). Guidelines for exposure assessment. Washington, DC: Risk Assessment Forum, U.S. Environmental Protection Agency.

Vegesna, S. R., \& McAnally, S. A. (1995). Corrosion indices as a method of corrosion measurement and a systems operating tool. Journal of Environmental Science and Health .Part A: Environmental Science and Engineering and Toxicology, 30(3), 583. http://dx.doi.org/10.1080/10934529509376219

White, L. D., Cory-Slechta, D. A., Gilbert, M. E., Tiffany-Castiglioni, E., Zawia, N. H., Virgolini, M., ... Bashae, R. (2007). New and evolving concepts in the neurotoxicology of lead. Toxicology and Applied Pharmacology, 225(1), 1-27. http://dx.doi.org/10.1016/j.taap.2007.08.001

Williams, P., Benton, L., Warmerdam, J., \& Sheehans, P. (2002). Comparative risk analysis of six volatile organic compounds in california drinking water. Environmental Science \& Technology, 36(22), 4721-4728. http://dx.doi.org/10.1021/es020725y

Wong, C. S., \& Berrang, P. (1976). Contamination of tap water by lead pipe and solder. Springer New York.

World Health Organization. (1996). Guidelines for drinking-water quality. vol 2, health criteria and other supporting information. World Health Organization.

Zietz, B. P., Dassel de Vergara, J., \& Dunkelberg, H. (2003). Copper concentrations in tap water and possible effects on infant's health-Results of a study in lower saxony, Germany. Environmental Research, 92(2), 129-138. http://dx.doi.org/10.1016/S0013-9351(03)00037-9 